\title{
Sistem Keamanan Pelacakan Kendaraan Bermotor Menggunakan Raspberry Pi 3 Dengan Module GPS Secara Realtime Berbasis Web
}

\author{
Ahmad Aldi Setiawan ${ }^{1}$, Muksan Junaidi ${ }^{2}$ \\ Program Studi S1 Teknik Elektro, Sekolah Tinggi Teknologi Ronggolawe Cepu
}

Received : 10-12-2020

Reviewed : 30-12-2020

Online Published : 31-12-2020

\begin{abstract}
Motor vehicle theft is a criminal problem that very often occurs in the community. Along with the development of technology and the level of demand for motor vehicle safety in the community that begins to increase. One of the devices that has been developed is Internet of Things (IoT) technology which is able to connect and facilitate the communication process between machines, devices and humans via the internet network. The purpose of this research is to develop a monitoring application that utilizes IoT technology as a medium for tracking the location of motorized vehicles. This research consists of 3 main system components, including the End Device System found on the Raspberry Pi device, Web Service (Back-End System) as a service for data transfer, and Front-End System user interface in the form of a website application. This system has several main features, including realtime tracking and is equipped with an activity log which can be used to determine the identity of the vehicle user. Users can access these features through the application from the website. Based on the trials conducted, this system works well on motorized vehicles, however, this system has more dependence on the internet network available in each region.
\end{abstract}

Keywords: Raspberry Pi 3, Real-time Tracking, Internet of Things

\section{Pendahuluan}

Jumlah kebutuhan alat transportasi, khususnya kendaraan bermotor di indonesia dari tahun ketahun mengalami peningkatan yang sangat signifikan. Kendaraan bermotor ini sudah menjadi kebutuhan orang-perorang pada setiap keluarga di kota maupun di pedesaan. Hal ini tingkat mobilisasi setiap orang akibat aktivitas ekonomi, sosial, dan sebagainya yang memerlukan kecepatan waktu. Dalam bidang perdagangan dan bisnis, transportasi merupakan tulang punggung pengerak aktifitas perekonomian nasional, regional, dan lokal, baik di perkotaan maupun di pedesaan.

Pada kenyataanya, berita terjadi pencurian kendaraan bermotor sering kita dengar di media sosial dan televisi, hal ini menjadi persoalan sehari-hari yang masih perlu dicarikan solusinya. Pencurian kendaraan bermotor dapat terjadi karena salah satunya adalah pemilik kendaran kurang teliti pada saat memarkirkan kendaraan. Pemilik kendaraan mengandalkan pada sistem keamanan konvensional yang sudah terpasang disetiap kendaraan, yakni pemilik sudah meyakini ketika kunci kontak sudah di posisi off dan mengunci stang kendaraan. Keadaan ini belum bisa menjamin bahwa kendaraan tersebut akan aman dan terhindar dari tindakan pencurian yang setiap saat mengintai. Dari dari data tahun 2016-2018, Pusat Badan Statistik (BPS) mencatat pencurian kendaraan bermotor sering terjadi diseluruh wilayah Indonesia (www.bps.co.id, 12-12-2019) dan dari data Operasi Sikat Jaran Candi 2020 yang digelar 06 Juli-25 Juli 2020 oleh Polres Blora, telah berhasil mengamankan 10 pelaku berikut 17 barang bukti sepeda motor di 6 Kecamatan di wilayah Kabupaten Blora, berita didalam (bloranews.com, 3-08-2020). Beberapa kasus pencurian kendaraan bermotor yang hampir setiap hari terjadi di lapangan selalu kita dengar dari berita-berita di media masa, baik media elektronik maupun cetak.
Seiring dengan perkembangan teknologi dan tingkat kebutuhan keamanan kendaraan bermotor di masyarakat yang mulai meningkat. Sebagai gambaran, bahwa sekarang sudah berkembang teknologi Internet of Things (IoT) yang mampu menyambungkan dan memudahkan proses komunikasi antara mesin, perangkat dan manusia melalui jaringan internet. IoT merupakan singkatan dari "Internet of Things" dimana setiap sistem memungkinkan untuk dikontrol dan dipantau dari jarak jauh. Data pada teknologi IoT terpusat pada sebuah server dan bersifat online.

Beberapa penelitian terdahulu yang berhubungan dengan pemanfaatan teknologi IoT untuk keamanan peralatan kendaraan maupun peralatan lainnya diantaranya : penelitian Manurung, J. (2019) bejudul "Sistem keamanan sepeda motor berbasis gps dan android". Penelitian Priyanggodo, D. T. (2019) berjudul "Pemanfaatan GPS Sebagai Sarana Mendapatkan Pertolongan Ketika dalam Kondisi Bahaya dengan Algoritma Divide and Conquer untuk Menentukan Lokasi Terdekat". Penelitian Sukarjadi, et al (2019), dengan judul "Rancang bangun alat pelacakan pencurian kendaraan berbasis gps menggunakan mikrokontroller (Arduino)". Penelitian Juwariyah, T., et al (2019), dengan judul "Purwa Rupa Sistem Pengaman Sepeda Motor Berbasis (IoT) Internet of Things" Penelitian Kurniawan, D. E., et al (2017), dengan judul "Sistem Pengaman Sepeda Motor Berbasis Perangkat Bergerak dengan Notifikasi dan Kendali Mesin".

Beberapa penelitian yang sudah dilakukan diatas memakai perangkat arduino uno yang dapat mengirimkan atau memberikan informasi koordinat lokasi kendaraan secara realtime. Salah satu usaha untuk mengatasi kasus pencurian tersebut adalah dengan cara menambahkan sistem keamanan pada kendaraan bermotor tersebut menggunakan perangkat GPS untuk melacak lokasi kendaraan bermotor secara real-time. 
Berdasarkan latar belakang permasalahan di atas, maka peneliti kali ini mencoba mengembangkan dan membuat suatu sistem keamanan yang bisa melacak dimana lokasi kendaraan bermotor tersebut menggunakan Raspberry pi 3 yang mempunyai fungsi untuk menggantikan komputer agar lebih canggih dan dengan module GPS sehingga user dapat mengetahui posisi kendaraan itu berada. Sistem ini, nantinya dapat dipergunakan untuk melacak lokasi kendaraan secara real-time yang terhubung melalui jaringan internet menggunakan aplikasi pendukung yang mudah diakses yaitu berbasiskan Web. Berdasarkan uraian diatas, maka penulis mengambil judul Tugas Akhir "SISTEM KEAMANAN PELACAKAN KENDARAAN BERMOTOR MENGGUNAKAN RASPBERRY PI 3 DENGAN MODULE GPS SECARA REALTIME BERBASIS WEB".

\section{Kerangka Teori}

\subsection{Internet of Things (IOT)}

Internet of Things, atau dikenal juga dengan singkatan IoT, merupakan sebuah konsep yang bertujuan untuk memperluas manfaat dari konektivitas internet yang tersambung secara terus-menerus. Adapun kemampuan seperti berbagi data, remote control, dan sebagainya, termasuk juga pada benda di dunia nyata (Bahga, A., \& Madisetti, V. 2014).

\subsection{Raspberry Pi}

Raspberry $P i$, sering disingkat dengan nama Raspi, adalah komputer papan tunggal (single-board circuit; SBC) yang seukuran dengan kartu kredit yang dapat digunakan untuk menjalankan program perkantoran, permainan komputer, dan sebagai pemutar media hingga video beresousi tinggi (Dinata, A. 2017).

\subsection{Python}

Python adalah bahasa pemrograman interpretatif multiguna dengan filosofi perancangan yang berfokus pada tingkat keterbacaan kode. Python diklaim sebagai bahasa yang menggabungkan kapabilitas, kemampuan, dengan sintaksis kode yang sangat jelas, dan dilengkapi dengan fungsionalitas pustaka standar yang besar serta komprehensif (Lutz, M. 2001).

\subsection{Flask}

Flask adalah framework web pada Phyton yang kecil namun tangguh. Flask mudah dipelajari dan digunakan. Flask berfungsi sebagai kerangka kerja aplikasi dan tampilan dari suatu web, dengan menggunakan flask dan bahasa phyton pengembang dapat membuat sebuah web yang terstruktur dan dapat mengatur suatu web dengan mudah (Grinberg, $\mathbf{M}$. 2018).

\subsection{SQLite}

SQLite merupakan sebuah database yang bersifat ACIDcompliant dan memiliki ukuran pustaka kode yang relatif kecil, ditulis dalam bahasa C. SQLite merupakan proyek yang bersifat public domain yang dikerjakan oleh D. Richard Hipp (Owens, M., \& Allen, G. 2010).
Socket.iomerupakan sebuah library javascript yang membantu dalam pembuatan aplikasi web yang realtime lebih mudah, dengan menggunakan socket.io kita dapat menghubungkan antara client dan server dapat terjadi secara bidirectional dua arah (Rai, R. 2013).

\subsection{Representational State Transfer (REST)}

REST merupakan arsitektur web service yang dikembangkan dari beberapa gaya arsitektur berbasis jaringan yang sering diterapkan dalam layanan berbasis web. Arsitektur REST pada umumnya dijalankan melalui HTTP (Hypertext Transfer Protocol), melibatkan proses pembacaan web page tertentu yang memuat sebuah file $X M L$ atau JSON. Setiap permintaan bersifat independen, server tidak menyimpan keadaan permintaan apapun (Richards, R. 2006).

\subsection{JSON Web Token (JWT)}

JWT merupakan sebuah token berbentuk string yang terdiri dari tiga bagian yaitu : header, payload, dan signature yang digunakan untuk proses otentikasi dan pertukaran informasi. Token terdiri dari dua jenis : token pembawa dan token pemegang kunci. Sedangkan berdasarkan tujuan terdapat dua skema yaitu token identitas dan token akses (Smith, B. 2015).

\subsection{Sistem Informasi}

Sistem diartikan sebagai kumpulan dari komponen yang saling berkaitan untuk secara bersama-sama menghasilkan satu tujuan. Mengenai hirarki pengelompokkannya, dapat dikemukakan bahwa apabila suatu komponen di dalam suatu sistem membentuk sistem sendiri maka komponen ini dinamakan subsistem dan seterusnya sehingga akan ada nama-nama modul, sub modul, aplikasi dan sub aplikasi (Sutabri, T. 2012).

\subsection{Systems Development Life Cycle (SDLC)}

Siklus Hidup Pengembangan Sistem atau Systems Life Cycle (Siklus Hidup Sistem), dalam rekayasa sistem dan rekayasa perangkat lunak, adalah proses pembuatan dan pengubahan sistem serta model dan metodologi yang digunakan untuk mengembangkan sistem-sistem tersebut. Konsep ini umumnya merujuk pada sistem komputer atau informasi (Rock-Evans, R. 2014). SDLC juga merupakan pola yang diambil untuk mengembangkan sistem perangkat lunak, yang terdiri dari tahap-tahap: rencana (planning), analisis (analysis), desain (design), implementasi (implementation), uji coba (testing) dan pengelolaan (maintenance).

\section{Metodologi}

Pada tahap metodologi dilakukan proses studi literature dan observasi. Setelah itu pengolahan data (perancangan sistem) dan analisi dari hasil sistem tersebut.

\subsection{Desain Penelitian}

Diagram alir penelitian diperlukan untuk melakukan perencanaan proses, analisis proses, dan dokumentasi proses sebagai pedoman untuk melakukan penelitian, berikut diagram alir penelitian yang ditampilkan pada Gambar 1 :

\subsection{Socket.io}



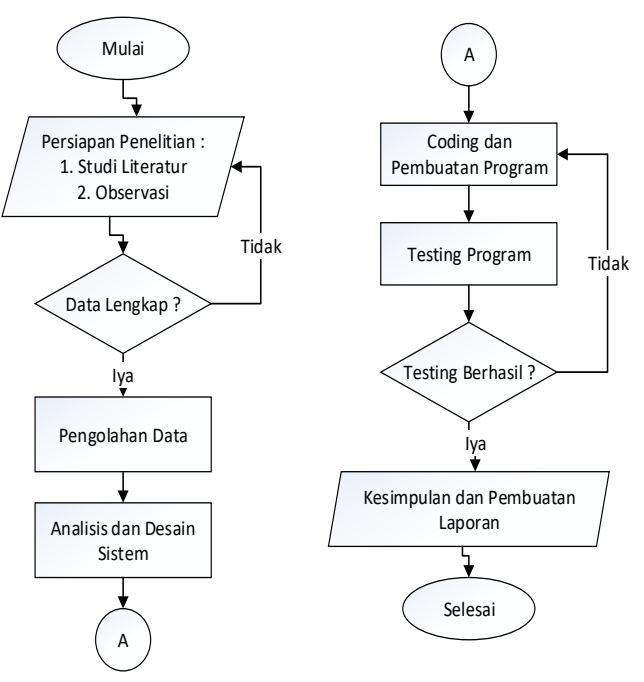

Gambar 1. Diagram Alir Penelitian

\subsubsection{Metode Pengumpulan Data}

Dalam penelitian ini menggunakan metode pengumpulan data yang meliputi :

a. Metode Literatur

Studi Literatur ini dilakukan oleh penulis untuk mendapatkan masukan mengenai topik permasalahan pada penelitian yang akan dilakukan, antara lain dengan melakukan membaca referensi, serta melakukan diskusi dengan dosen pembimbing.

b. Metode Observasi

Observasi yang dilakukan oleh peneliti adalah dengan mengamati secara langsung terhadap objek penelitian. Observasi dilakukan untuk memperoleh informasi secara langsung terhadap permasalahan yang sedang diteliti untuk menentukan sistem yang benar-benar sesuai.

\subsubsection{Sumber Data Penelitian}

Semua data dalam penelitian ini diambil dari ruang lingkup masyarakat sekitar kota cepu mau pun Sekolah Tinggi Teknologi Ronggolawe Cepu.

\subsection{Analisi dan Perancangan Sistem}

\subsubsection{Diagram Konteks Sistem Yang Sedang Berjalan}

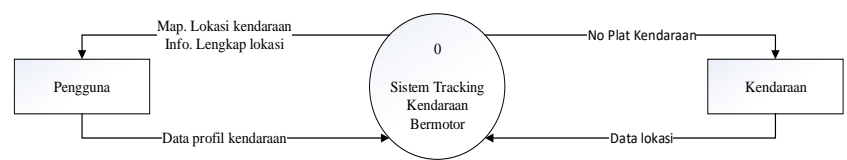

Gambar 2. Diagram Konteks Tracking Kendaraan Bermotor Yang Sedang Berjalan

System Tracking kendaraan bermotor ini mempunyai dua entitas yaitu pengguna dan kendaraan, dibagian kendaraan sudah dipasang system raspberry pi dengan module gps. Sistem kendaraan akan mengirim info lokasi ke aplikasi system tracking kendaraan bermotor sehingga pengguna dapat mengetahui info lengkap dari aplikasi web tersebut.

\subsubsection{Data Flow Diagram Sistem Yang Sedang Berjalan}

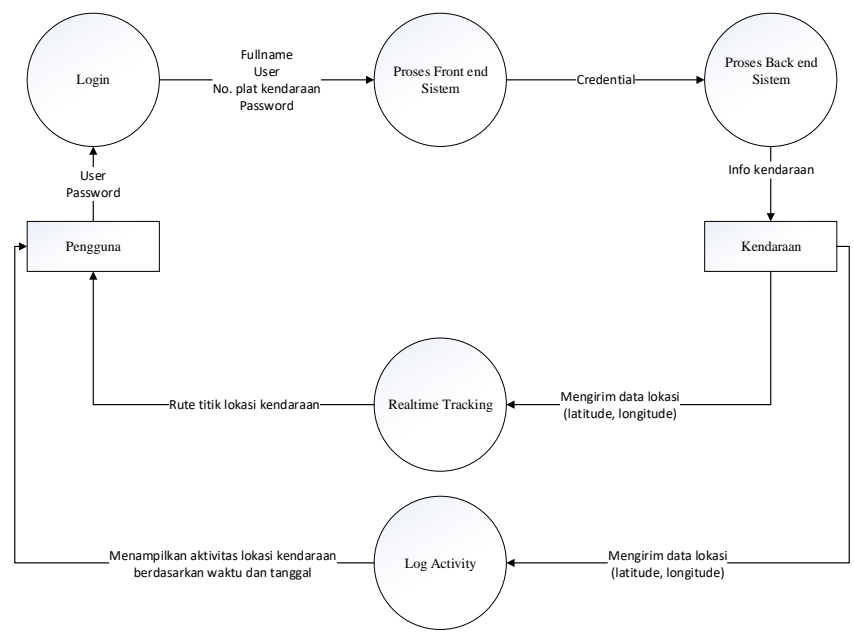

Gambar 3. Data Flow Dagram Level 1 Tracking Kendaraan Bermotor yang Sedang Berjalan

Prosedur yang sedang berjalan pada system tracking kendaraan bermotor yaitu :

1. Pengguna menginput profil kendaraan

2. System back end merupakan keseluruhan system yang terdapat pada server. Server yang digunakan pada penelitian ini berbasis Python dan dikirim ke kendaraan bermotor yang terdapat sistem pada perangkat raspberry pi. Pada bagian ini, raspberry pi akan dihubungkan dengan module gps.

3. Realtime Tracking system yang terdapat pada perangkat raspberry $p i$ dikendaraan bermotor mengirim data lokasi yang sudah ditangkap module gps dan pengguna akan bisa mengetahui gambaran maps lokasi kendaraan bermotor tersebut.

4. Log Tracking system yang terdapat pada perangkat raspberry pi dikendaraan bermotor mengirim data lokasi yang sudah ditangkap module gps, pengguna bisa mengetahui rute lokasi kendaraan bermotor tersebut.

5. Log Activity system yang terdapat pada perangkat raspberry pi dikendaraan bermotor mengirim data lokasi yang sudah ditangkap module gps, pengguna bisa mengetahui aktivitas waktu kendaraan yang sedang berhenti.

\subsubsection{Entity Relationship Diagram (ERD) Sistem Yang Sedang Berjalan}

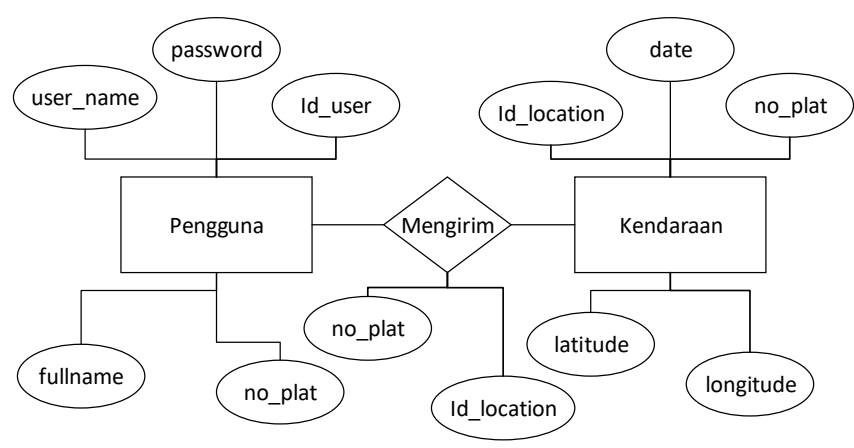


Gambar 4. Entity Relationship Diagram Sistem Yang Sedang Berjalan Pada Aplikasi Tracking Kendaraan Bermotor

\subsubsection{Struktur Tabel Sistem Yang Sedang Berjalan}

1. Tabel User

Tabel 1. Struktur Tabel User

\begin{tabular}{|l|l|l|l|}
\hline \multicolumn{1}{|c|}{ Field } & \multicolumn{1}{c|}{ Type } & \multicolumn{1}{c|}{ Null } & \multicolumn{1}{c|}{ Default } \\
\hline id_user & INTEGER & No & None \\
\hline username & VARCHAR & No & None \\
\hline password & VARCHAR & No & None \\
\hline Fullname & VARCHAR & No & None \\
\hline no_plat & VARCHAR & No & None \\
\hline
\end{tabular}

2. Tabel Location

Tabel 2. Struktur Tabel Location

\begin{tabular}{|l|l|l|l|}
\hline \multicolumn{1}{|c|}{ Field } & \multicolumn{1}{c|}{ Type } & \multicolumn{1}{c|}{ Null } & \multicolumn{1}{c|}{ Default } \\
\hline id_location & INTEGER & No & None \\
\hline Latitude & FLOAT & No & None \\
\hline Longitude & FLOAT & No & None \\
\hline no_plat & VARCHAR & No & None \\
\hline Date & INTEGER & No & None \\
\hline
\end{tabular}

\subsubsection{Diagram Skmatik Raspberry Pi dan Module GPS}

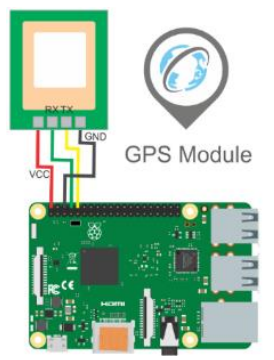

Gambar 5. Desain Sistem Raspberry Pi Dan Module Gps

Vcc $=$ Gpio 2, Gnd $=$ Gpio 6, Rx $=$ Gpio 8, Tx $=$ Gpio 10

Untuk menghubungkan module GPS dengan Raspberry Pi, kita perlu menggunakan serial UART (port Rx dan Tx). Pin $R x$ atau Receiver digunakan untuk menerima data, dan $T x$ atau Transmitter digunakan untuk mengirimkan data. Untuk melakukan komunikasi serial ini, port Rx dari Raspberry Pi harus dihubungkan dengan port Tx pada GPS module, begitu pula sebaliknya port Tx pada Raspberry harus dihubungkan dengan Rx pada GPS module. Module GPS ini membutuhkan tegangan $3.5 \mathrm{v}$, namun di beberapa referensi menyebutkan bahwa module Neo Ublox $6 M V 2$ ini juga dapat menggunakan tegangan 5v dari Raspberry Pi.

\subsubsection{Diagram Skematik Sistem Yang Sedang Berjalan}

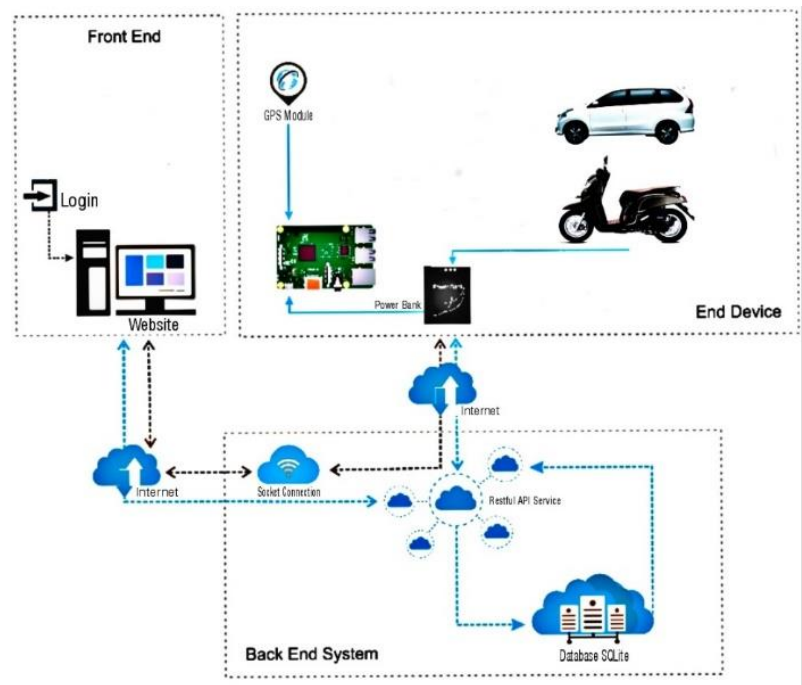

Gambar 6. Desain Sistem

Sistem pada penelitian ini terbentuk dari 3 buah bagian sistem utama, yaitu End Device System, Back-End System, dan Front-End System.

\subsubsection{Desain Menu Aplikasi Pelacakan Kendaraan Bermotor}

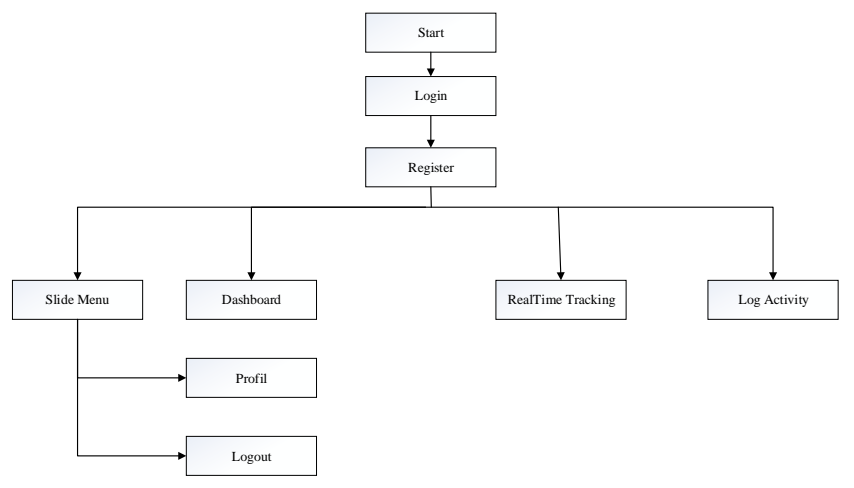

Gambar 7. Rancangan Website

\section{Hasil dan Pembahasan}

\subsection{Instalasi Operating System (OS)}

Didalam system raspberry pi diinstalasi OS yaitu Rasbian.

\subsubsection{Implementasi Relasi Database}

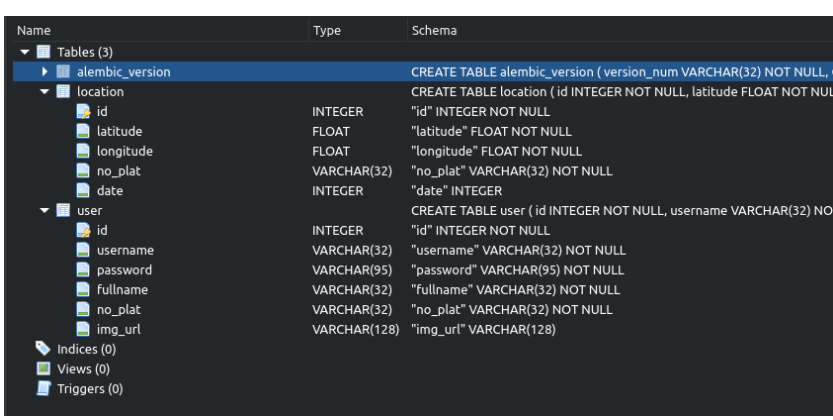

Gambar 8. Tabel Database SQLite 


\subsubsection{Implementasi Antarmuka}

Implementasi antarmuka merupakan hasil program berdasarkan sistem yang telah dirancang. Berikut dibawah ini implementasi antarmuka adalah sebagai berikut:

\section{- Halaman Login}

Halaman login ditujukan untuk pengguna. Pengguna harus memasukkan username dan password. Halaman login Sistem tracking kendaraan bermotor ditampilkan pada Gambar 9.

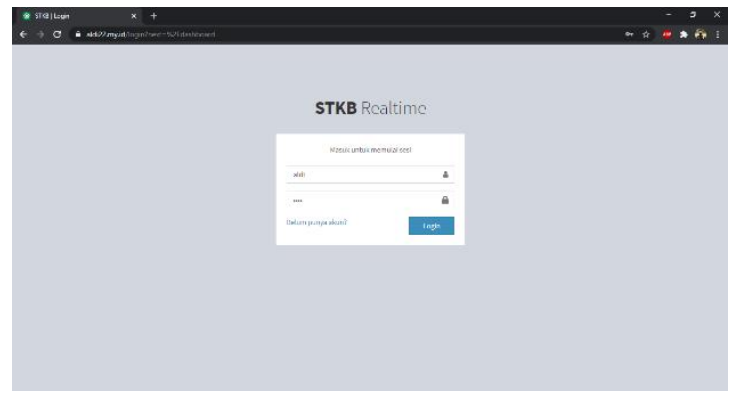

Gambar 9. Halaman Login

- Halaman Register

Halaman register ditujukan untuk pengguna. Pengguna yang belum pernah daftar harus memasukkan identitas diri dan kendaraan. Halaman register Sistem tracking kendaraan bermotor ditampilkan pada Gambar 10.

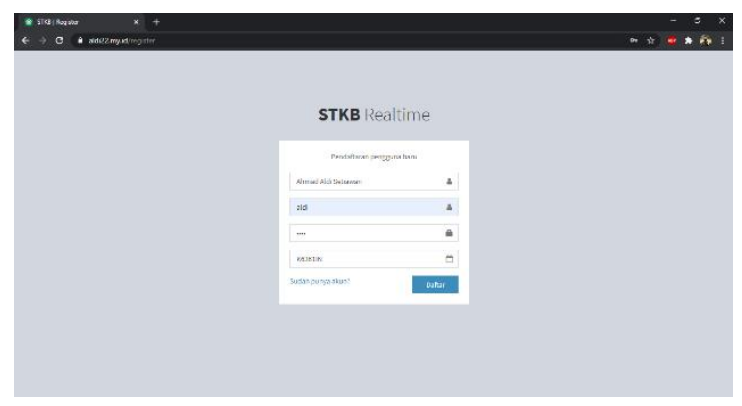

Gambar 10. Halaman Register

- Halaman Perbarui Profil

Halaman perbarui profil ditujukan pengguna untuk memperbarui foto profil, password, identitas diri dan kendaraan . Halaman perbarui profil Sistem tracking kendaraan bermotor ditampilkan pada Gambar 11.

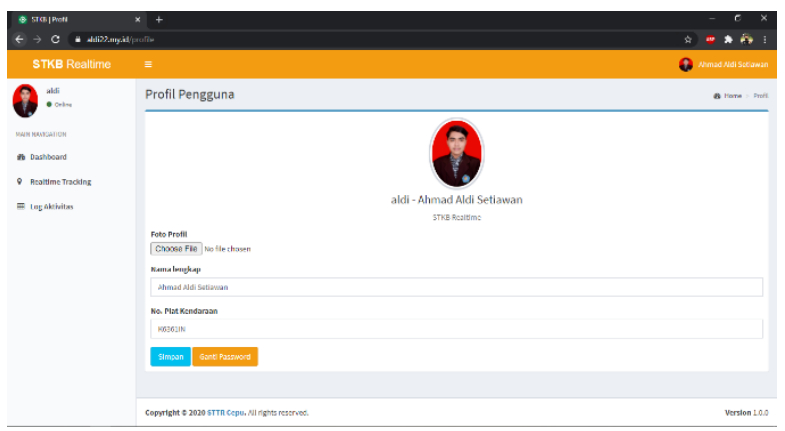

Gambar 11. Halaman Perbarui Profil
- Halaman Dashboard

Halaman dashboard ditujukan pengguna masuk di tampilan utama. Halaman perbarui profil Sistem tracking kendaraan bermotor ditampilkan pada Gambar 12.

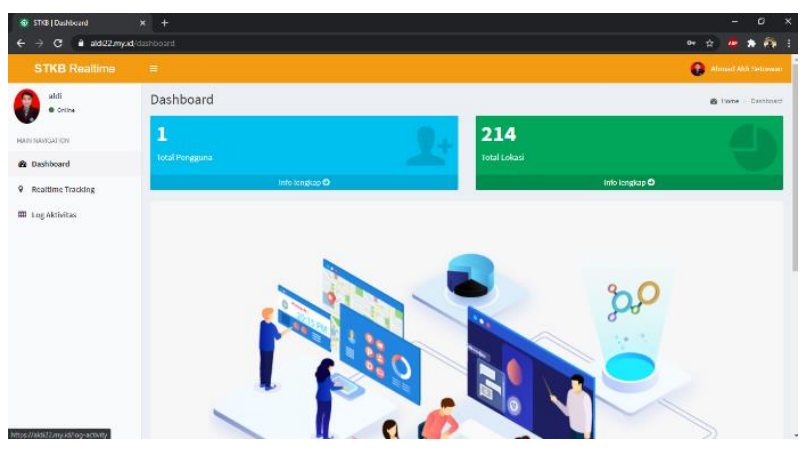

Gambar 12. Halaman Dashboard

- Halaman Tracking Realtime

Halaman tracking realtime ditujukan untuk melihat rute titik lokasi kendaraan secara realtime. Halaman tracking realtime Sistem tracking kendaraan bermotor ditampilkan pada Gambar 13.

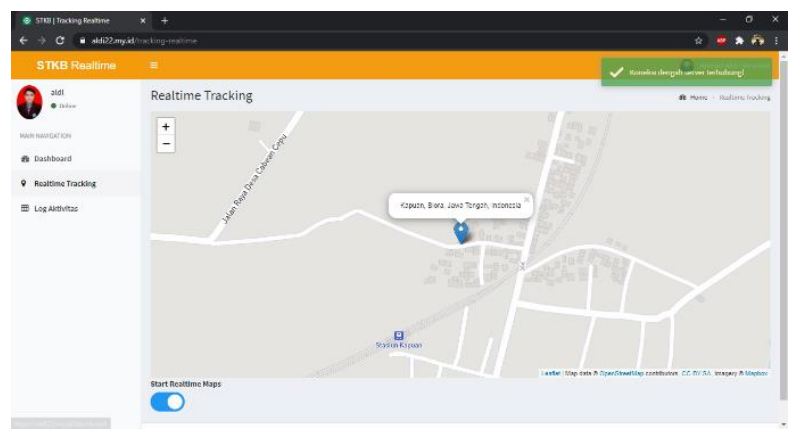

Gambar 13. Halaman Tracking Realtime

- Halaman Log Activity

Halaman log activity ditujukan untuk melihat data tabel identitas diri, data lokasi, log tracking, tanggal dan waktu. Halaman log activity Sistem tracking kendaraan bermotor ditampilkan pada Gambar 14.

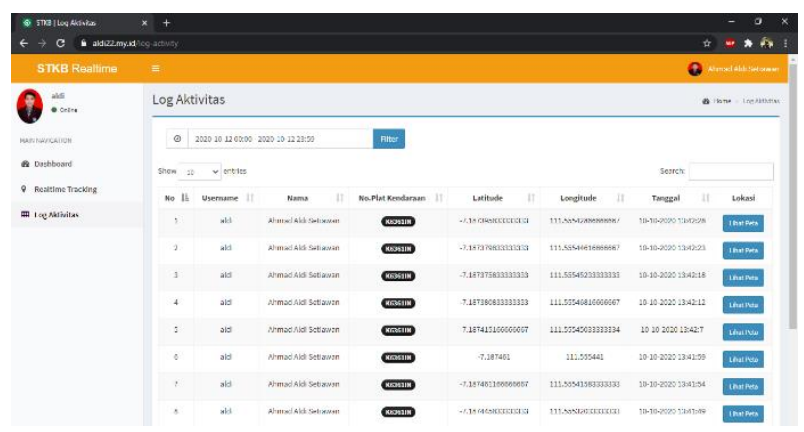

Gambar 14. Halaman Log Activity

- Halaman Tombol Profil dan Logout

Halaman tombol profil dan logout ditujukan untuk melakukan masuk halaman profil dan logout. Halaman tombol profil dan logout Sistem tracking kendaraan bermotor ditampilkan pada Gambar 15. 


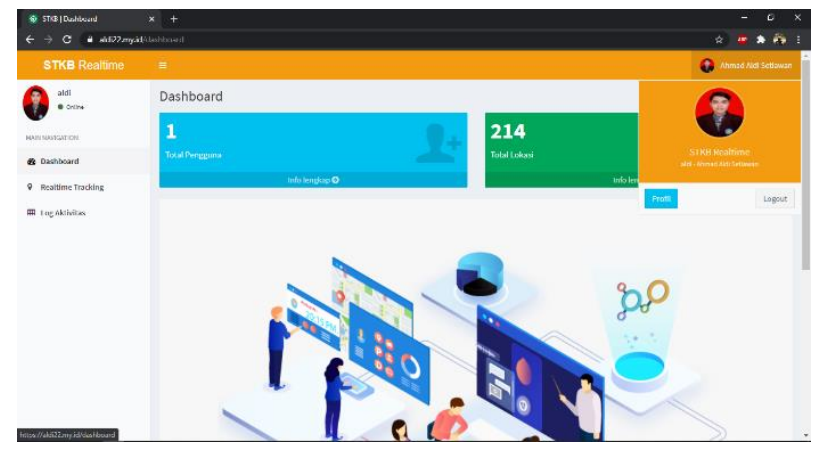

Gambar 15. Halaman Tombol Profil Dan Logout

\section{Simpulan}

Dari hasil pengamatan mulai dari perancangan sistem, pembuatan sistem, dan impelementasi, dapat ditarik beberapa kesimpulan sebagai berikut :

1. Hasil pengujian, memperlihatkan bahwa sistem dapat menampilkan halaman log activity untuk memonitor pergerakan objek kendaraan, berisi informasi : data tabel identitas diri, data lokasi, log tracking, tanggal dan waktu.

2. System ini dapat menampilkan halaman tracking realtime untuk melacak lokasi objek kendaraan yang dimonitor, sehingga akan mempermudah pemilik dalam mengetahui keberadaan lokasi objek kendaraan dengan melihat tampilan rute titik lokasi kendaraan secara realtime.

3. Tingkat keberhasilan pengiriman data dari lokasi objek kendaraan ke aplikasi, sangat dipengaruhi oleh koneksi internet, dan data yang diperoleh yang berhasil ditangkap oleh module.

4. Hasil penujian kelayakan sistem dari sisi karakteristik functionality (sub karakteristik suitability dan accuracy) bernilai $97,6 \%$ dan memiliki interpretasi Sangat Baik

\section{Ucapan Terima Kasih}

Ucapan terima kasih ditujukan kepada dosen pembimbing yang telah mengarahkan dan membimbing dalam penelitian tugas akhir ini, serta semua pihak yang namanya tidak dapat disebutkan satu-persatu yang telah membantu dalam keberlangsungan penelitian tugas akhir ini.

\section{Daftar Pustaka}

Bahga, A., \& Madisetti, V. 2014. Internet of Things: A hands-on approach. Vpt.

Chaffer, J. 2013. Learning jQuery. Packt Publishing Ltd.

Chen, P. P., \& Chen, P. 1977. The entity-relationship approach to logical data base design (Vol. 6, p. 33). Wellsley, Massachusetts: QED information sciences.

Dinata, A. 2017. Physical Computing dengan Raspberry Pi. Elex Media Komputindo.

Grinberg, M. 2018. Flask web development: developing web applications with python. " O'Reilly Media, Inc.".

Hartono, J. 2005. Analisis Dan Desain Sistem Informasi : Pendekatan Tersktruktur \& Praktek Aplikasi Bisnis. Yogyakarta: Andi.

https://databoks.katadata.co.id/datapublish/2016/12/23/2015-kasuscuranmor-jawa-barat-tertinggi

https://www.bloranews.com/10-pelaku-curanmor-berhasil-dibekuksatreskrim-polres-blora/

Juwariyah, T., Widiyanto, D., \& Sulasmingsih, S. 2019. Purwa Rupa Sistem Pengaman Sepeda Motor Berbasis IoT (Internet of Things. Jurnal Otomasi, Kontrol, dan Instrumentasi, 11(1), 49-57.

Kurniawan, D. E., \& Surur, M. N. 2017. Sistem Pengaman Sepeda Motor Berbasis Perangkat Bergerak dengan Notifikasi dan Kendali Mesin. Sriwijaya Journal of Information Systems, 9(1), 131767.

Li, Q., \& Chen, Y. L. 2009. Data flow diagram. In Modeling and Analysis of Enterprise and Information Systems (pp. 85-97). Springer, Berlin, Heidelberg.

Lutz, M. 2001. Programming python. " O'Reilly Media, Inc.".

Manurung, J. 2019. Sistem Keamanan Sepeda Motor Berbasis GPS Dan Android. Sigma Teknika, 2(2), 242-249.

Owens, M., \& Allen, G. 2010. SQLite. Apress LP.

Priyanggodo, D. Y. 2019. Pemanfaatan GPS Sebagai Sarana Mendapatkan Pertolongan Ketika dalam Kondisi Bahaya dengan Algoritma Divide and Conquer untuk Menentukan Lokasi Terdekat.JIKA (Jurnal Informatika), 3(1).

Prastiyo, A., \& Madyono, M. 2019. Rancang Bangun Alat Pelacakan Pencurian Kendaraan Berbasis GPS Menggunakan Mikrokontroler (Arduino). Jurnal Nasional Aplikasi Teknik untuk Industri, 2(01).

Rai, R. 2013. Socket. IO Real-time Web Application Development. Packt Publishing Ltd.

Richards, R. 2006. Representational state transfer (rest). In Pro PHP XML and web services (pp. 633-672). Apress, Berkeley, CA.

Rock-Evans, R. 2014. Analysis within the Systems Development Life-Cycle: Book 4 Activity Analysis-The Methods. Elsevier.

Sianipar, R. H. 2015. Pemrograman Javascript: Teori Dan Implementasi (Vol. 1). Penerbit INFORMATIKA.

Smith, B. 2015. Beginning JSON. Apress.

Sutabri, T. 2012. Analisis sistem informasi. Penerbit Andi. 